\title{
An Experimental Investigation of DI Diesel Engine Fuelled with Emulsions of Mahua Bio-Oil
}

\author{
Hanumanth Mulimani ${ }^{1}$, M. C. Navindgi ${ }^{2}$ \\ ${ }^{1,2}$ Department of Mechanical Engineering, PDA College of Engineering, Kalburgi, Karnataka. India
}

\begin{abstract}
This paper describes the performance and emission parameters of a DI diesel engine fuelled with Mahua Bio-Oil (MBO) diesel emulsion with Diethyl Ether (DEE) as an ignition improver and tween 20 as surfactant. An attempt was made to use emulsified bio-oil with diesel fuel in a single cylinder, four stroke, water cooled, DI diesel engine. The performance and exhaust emissions were measured from the diesel engine at different power outputs. The performance and exhaust emissions were studied from the engine with diesel and four different $M B O$ emulsions. BTE of the engine operated with MBO emulsions was found to be higher than that of diesel. EGT is found to be more when compared to diesel and was increasing with increased emulsions. The smoke and NO emissions are found to be reduced in the case of emulsions when compared with that of diesel.
\end{abstract}

Keywords: Pyrolysis, Bio-oil, Ignition improver, Surfactant

\section{Introduction}

The developing countries are focusing for alternative fuels for compression ignition engines to replace fossil fuel. Biomass and residues can be converted to more valuable energy forms via a number of processes including thermal, biological and mechanical processes. Pyrolysis has been receiving more attention as an efficient method in converting biomass into bio fuel during recent decades [1]-[3]. Bio oil from pyrolysis is considered as one of the alternate fuel.

Pyrolysis is the thermal decomposition of materials in the absence of oxygen or when significantly less oxygen is present than required for complete combustion. Pyrolysis is difficult to precisely define, especially when applied to biomass. The term pyrolysis often describes processes in which oils are preferred products [4]. In the pyrolysis process, the feed stock is heated in a closed chamber or vessel with an external heat source. The volatile matter that evolves in the vessel is further condensed to get value added products, such as secondary fuels and chemicals that are obtained in the form of liquids, gases and solids [5].

Many attempts have been made to extract mahua biodiesel from the mahua seeds, the same biodiesel was used effectively as an alternative fuel without any engine modifications. They found the performance, emission and combustion characteristics of DI diesel engine were as par with diesel fuel [6]. The seed cake left can be better utilized to produce the liquid fuel called as pyrolytic oil or bio-oil from the pyrolysis of various biomass sources like karanja seed, Rapeseed, Agricultural residues [7]-[9].

It was found that the bio-oil would not auto-ignite without an ignition additive and therefore a nitrated alcohol is added in various concentrations to the bio-oil. A minimum of $5 \mathrm{vol}$. $\%$ additive was required for stable engine [10].

It was observed that, although pyrolysis oil was hard to ignite, it burned readily after the combustion had begun. Bio-oil with 5\% ignition improver gave, more or less, the same exhaust performance as conventional diesel fuel and better emission performance than the reference fuel (RF35) with poor ignition quality [11].

Due to the presence of oxygenated compounds in the bio-oil, it cannot be blended with the conventional oil. Bio-oil can be combined with diesel fuel directly through emulsification method by the aid of surfactant. Many surfactants such as Ampholak, Armotan, Carbopol, Hypermer, Tween 20 and Span 20 have been reported to form stable emulsions. When an emulsion is prepared, the choice of the emulsification method and the selection of the most appropriate surfactant represent the key-factors in obtaining a stable dispersion. As they are expected to offer the advantages (compared to crude bio-oil) like easier ignition, easier transportation, handling and storage, lower viscosity, improved stability against aging [12].

Vikranth Volli et. al. [13] conducted experiment on a single cylinder, four stroke, air cooled IC engine with $4.4 \mathrm{KW}$ brake power was run on diesel using Mustard Cake Pyrolytic Oil (MCPO) and its blends at a constant speed of 1,500 rpm under variable load conditions. There was a significant increase in brake thermal efficiency with slight increase in specific energy consumption when compared to diesel operation. Exhaust emissions including $\mathrm{CO}$, NOx were lower, making blends of MCPO (B30) a suitable alternative fuel for diesel.

Babita Singh et al. [14] conducted pyrolysis process with 1:1 ratio mixture of waste frying oil and castor oil. The pyrolysis oil obtained was blended with diesel fuel at different ratios and the performance and emission characteristics of a twin cylinder, four-stroke and water cooled, direct injection diesel engine were studied. Brake thermal efficiency using pyrolysis oil is higher than diesel. The brake thermal efficiency decreases with blending, but is more than diesel for every blending. The exhaust gas temperature increases with brake power. The exhaust gas temperatures were higher for blends than diesel. As the brake power increases the oxides of nitrogen emissions also increases. The oxides of nitrogen emissions were higher for pyrolysis oil blends than diesel. However the oxide of nitrogen emission decreases with blending. 


\section{International Journal of Science and Research (IJSR) \\ ISSN (Online): 2319-7064}

Index Copernicus Value (2015): 78.96 | Impact Factor (2015): 6.391

R.Prakash et. al. [15] conducted experiment emulsions made with Wood Pyrolysis Oil (WPO) and Jatropha Methyl Ester (JME) and observed that the brake thermal efficiency and brake specific fuel consumption of the emulsions are higher than that of diesel fuel. The BSFC values of the emulsions are also higher than diesel fuel. The Smoke, NO, green house gas emissions were less than the diesel fuel compared to the emulsions. P. Weerachanchai, et al. [16] in his study indicates that the blending of the palm kernel bio-oil with diesel by using alcohol as a co-solvent is a promising alternative fuel. The blended fuels of these ternary systems gave satisfactory fuel properties in spite of high amounts of alcohol being required for phase stability. However, the use of butanol as a co-solvent showed better characteristics of phase behaviour and fuel properties than by using ethanol.

The main concerns for operating diesel engines with bio-oils are some specific properties of these liquids bio-oils such as difficult ignition (resulting from low heating value and high water content), corrosiveness (acids) and coking (thermally unstable compounds) [10]. Use of bio-oil in diesel engines is far more limited due to the problems that arise when attempting to use this fuel in diesel engines. The problems are more specifically due to its higher viscosity and acidity, tars and fine particles it often contains and the formation of char and solid residues during its combustion. [15].

Major problem with the MBO is its miscibility with diesel fuel. The problem of immiscibility can be solved by upgradation of pyrolysis oil by emulsification process. Emulsion is one of the techniques used for mixing two different fuels, one with a hydroscopic nature. An emulsion was prepared for bio-oil with diesel fuel using a surfactant with $2 \%$ by volume. It was observed that a surfactant could be used to stabilize water in diesel mixture which cannot be maintained by natural mixing of diesel with water because of their different densities and forces of surface tension. Surfactants reduce the surface tension forces so that they permit two different densities of liquid to form a stable emulsion. Emulsion prepared with an addition of Tween 20 surfactant $2 \%$ by volume with four different percentages of water as fuels were tested in a diesel engine. In the present investigation DEE is used as ignition improver and Polysorbate 20 [Tween-20] as surfactant, used to prepare an emulsion of MBO with diesel. The emulsion of MBO and diesel was used as fuel in a single cylinder, direct injection diesel engine. The results are compared with diesel fuel operation and presented.

\section{Materials and Methods}

\subsection{Production and fuel properties of $\mathrm{MBO}$}

For the present experiment, MBO from de-oiled seed cake was obtained by pyrolysis process. Figure 1 show the steps involved in production of $\mathrm{MBO}$. The pyrolysis process for deriving MBO was carried out at $420-500{ }^{0} \mathrm{C}$. The products of pyrolysis in the form of vapour were sent to a water cooled condenser and the condensed liquid was collected in a container.

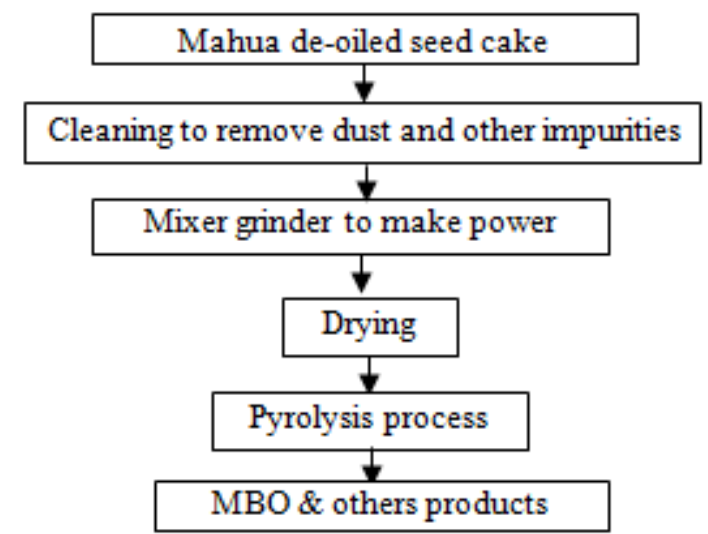

Figure 1: Production of Mauha Bio-oil

Table 1: Physical properties of bio-oil

\begin{tabular}{|l|l|}
\hline Properties & MBO \\
\hline Appearance & Dark Colored liquid \\
\hline Odor & Smoky smell \\
\hline Density at $15^{\circ} \mathrm{C}$ & $980 \mathrm{Kg} / \mathrm{m}^{3}$ \\
\hline Viscosity at $25^{0} \mathrm{C} \mathrm{cSt}$ & 10.2 \\
\hline Gross calorific value MJ $/ \mathrm{kg}$ & 30.948 \\
\hline Moisture content Wt. \% & 25.0 \\
\hline Ash Wt. $\%$ & 0.09 \\
\hline Flash Point ${ }^{0} \mathrm{C}$ & 116 \\
\hline
\end{tabular}

Table 1 shows the physical properties of bio-oil. The density of the crude bio-oil $\left(980 \mathrm{~kg} / \mathrm{m}^{3}\right)$ is higher than base diesel $\left(830 \mathrm{~kg} / \mathrm{m}^{3}\right)$. The higher fuel density would severely affect the spray characteristics of diesel engines resulting in poor mixing of fuel with air. The moisture content of the crude bio-oil is about $25 \%$ which is not desirable for diesel engine applications. Since the viscosity if bio-oil is $10.2 \mathrm{cSt}$ which is much higher than diesel $3.05 \mathrm{cSt}$, hence direct use of biooil is not suitable as an alternative fuel in diesel engine. MBO is denser, highly viscous and calorific value is less than the commercial fuels which makes it not suitable to use in diesel engines.

\subsection{Emulsification of $\mathrm{MBO}$}

Bio-oil is miscible with methanol, acetone, etc., but totally immiscible with petroleum-derived fuels (Dinesh Mohan, 2006). Major problem with the bio-oil is its miscibility with diesel fuel. The problem of immiscibility can be solved by up-gradation of bio-oil by emulsification process. It was observed that a surfactant could be used to stabilize water in diesel mixture which cannot be maintained by natural mixing of diesel with water because of their different densities and forces of surface tension. Surfactants reduce the surface tension forces so that they permit two different densities of liquid to form a stable emulsion. The stable emulsion can be prepared using many surfactants such as Ampholak, Armotan, Carbopol, Hypermer, Tween 20, and Span 20 [15]. In the present investigation Polysorbate 20 (Tween-20) $2 \%$ by volume is used to prepare an emulsion with diesel.

Emulsification is performed with a help of homogenizing unit. Energy input for homogenizing can be given by either shaking or stirring. The surfactant Polysorbate-20 commercially known as Tween-20 having hydrophiliclithophilic balance (HLB) number 16.7 was used as an 


\section{International Journal of Science and Research (IJSR) \\ ISSN (Online): 2319-7064}

Index Copernicus Value (2015): 78.96 | Impact Factor (2015): 6.391

emulsifier to emulsify bio-oil and diesel. For the preparation, first the surfactant is added to the diesel and then the bio-oil is added [15]. The resultant mixtures were shaken well to make a stable emulsion of BO10, BO20, BO30 and BO40.

Bio-Oil10\%-Diesel 80\%-DEE 8\%-Tween 2\% -BO10

Bio-Oil 20\%-Diesel 70\%-DEE 8\%-Tween 2\%-BO20

Bio-Oil 30\%-Diesel 60\%-DEE 8\%-Tween 2\%-BO30

Bio-Oil 40\%-Diesel 50\%-DEE 8\%-Tween 2\%-BO40

The physical properties of emulsified MBO emulsions obtained were having similar properties to the diesel as shown in table 2 .

Table 2: Physical properties of bio-oil emulsions

\begin{tabular}{|c|c|c|c|c|c|c|}
\hline \multirow{2}{*}{ Properties } & \multirow{2}{*}{ Diesel } & Crude & \multicolumn{4}{|c|}{ Up-graded bio-oil } \\
\cline { 4 - 7 } & & BO & BO10 & BO20 & BO30 & BO40 \\
\hline Calorific value MJ/kg & 43.8 & 30.9 & 41.2 & 39.2 & 36.4 & 35.6 \\
\hline Flash Point ${ }^{0} \mathrm{C}$ & 98 & 116 & 55 & 62 & 72 & 83 \\
\hline Density at $15^{\circ} \mathrm{C} \mathrm{Kg} / \mathrm{m}^{3}$ & 830 & 980 & 840 & 850 & 870 & 890 \\
\hline Viscosity at $25^{\circ} \mathrm{C} \mathrm{cSt}$ & 3.05 & 10.2 & 3.5 & 4.2 & 6.9 & 7.4 \\
\hline
\end{tabular}

\subsection{Experimental setup}

The experiments are planned to conduct on $5.2 \mathrm{~kW}$ TV-SR II, naturally aspirated, direct injection single cylinder water cooled having $50 \mathrm{~mm}$ bore and $110 \mathrm{~mm}$ stroke. Figure 2 shows the photograph of the experimental setup. It consists of a test bed, a diesel engine, an eddy current dynamometer, a data acquisition system, a computer, an operation panel, exhaust emission analysers, a smoke meter, and sensors to measure lubricating oil temperature, exhaust temperature at the manifold, a pressure sensor to measure in-line cylinder pressure, a pressure sensor to measure fuel line pressure. Two filters are installed, one at exit of tank and other one at fuel pump. The cooling water temperature is maintained constant (65 to $70 \mathrm{deg}$ ) throughout the research work by controlling the flow rate of fuel.

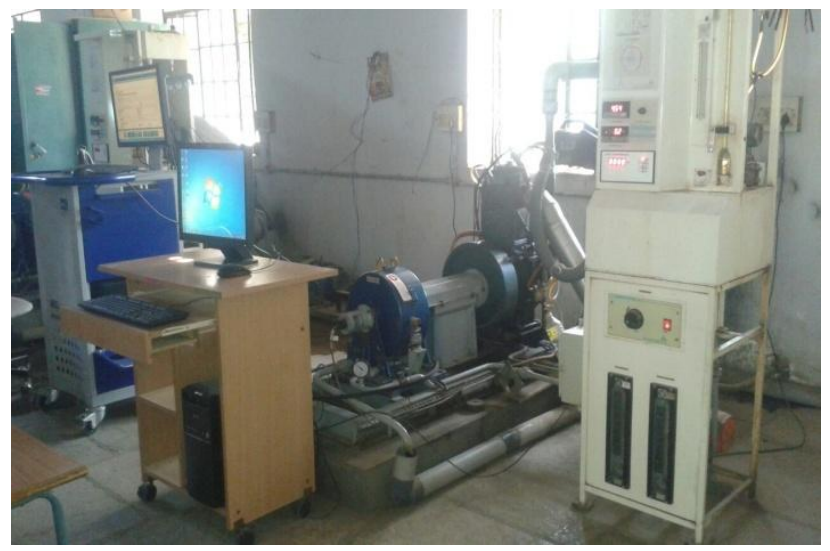

Figure 2: Photograph of the experimental setup Courtesy: PDACE, Kalburgi

The exhaust gas composition was analysed by using exhaust gas analyzer and smoke capacity with measurement range $\%: 0-1005$ with resolution was measured using smoke opacity meter. In cylinder pressure and TDC signals were acquired and stored on a high speed computer based design data acquisition system. The engine was tested at constant rated speed of $1500 \mathrm{rpm}$ throughout its power range using $\mathrm{BO} 10, \mathrm{BO} 20, \mathrm{BO} 30$ and $\mathrm{BO} 40$. Table 3 show the engine specification.
Table 3: Engine specifications

\begin{tabular}{|c|c|}
\hline Manufacturer & Kirloskar Engines Ltd.India, \\
\hline Model - AG -10 & TV-SR II \\
\hline Engine & Single cylinder, DI \\
\hline Bore/Stroke & $16.5 \mathrm{~mm} / 110 \mathrm{~mm}$ \\
\hline Compression ratio & $1500 \mathrm{rpm}$ \\
\hline Speed & $5.2 \mathrm{~kW}$ \\
\hline Rated power & Four \\
\hline Working cycles & $200 \mathrm{bar} / 23$ deg TDC \\
\hline Injection pressure & Piezo-electric \\
\hline Type of sensor & 2 micro seconds \\
\hline Response time & 1 deg crank angle \\
\hline Crank angle sensor & Water cooled engine \\
\hline Cooling & 360 deg encoder with 1 deg resolution \\
\hline Resolution of 1 deg
\end{tabular}

\section{Results and Discussion}

\subsection{Performance Parameters}

\subsubsection{Brake Thermal Efficiency (BTE)}

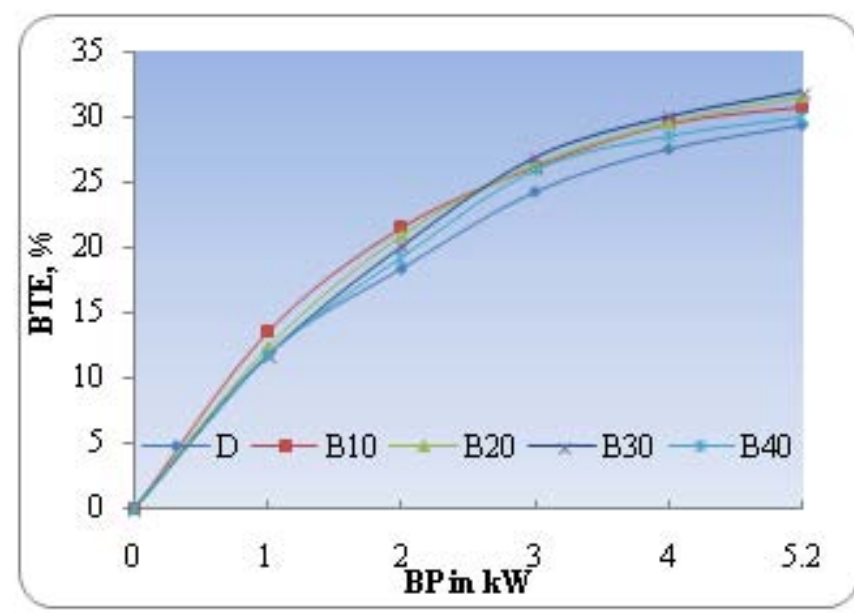

Figure 3: Variation of BTE with brake power

BTE of a diesel engine is the efficiency in which the chemical energy of a fuel is turned into useful work. It can be determined by dividing the useful work by the lower heating value of the fuel. Figure 3 gives the variation of BTE with brake power and it is clear that BTE increases with an increase in engine load. The BTE for diesel, BO10, BO20, BO30 and BO40 at full load are 29.48, 30.8, 31.8, 31.6 and $29.91 \%$ respectively. The BTE is higher for the emulsions compared to that of diesel at all loads. Addition of DEE to MBO emulsion will decrease the viscosity and may result in improvement in the shape of fuel spray and atomization. These finer fuel droplets tend to mix thoroughly with air and hence improving the combustion. It is evident from the graph the increase in the addition of DEE increases the brake thermal efficiency of the remaining emulsions as it is an ignition improver.

\subsubsection{Exhaust Gas Temperature (EGT)}




\section{International Journal of Science and Research (IJSR) \\ ISSN (Online): 2319-7064}

Index Copernicus Value (2015): 78.96 | Impact Factor (2015): 6.391

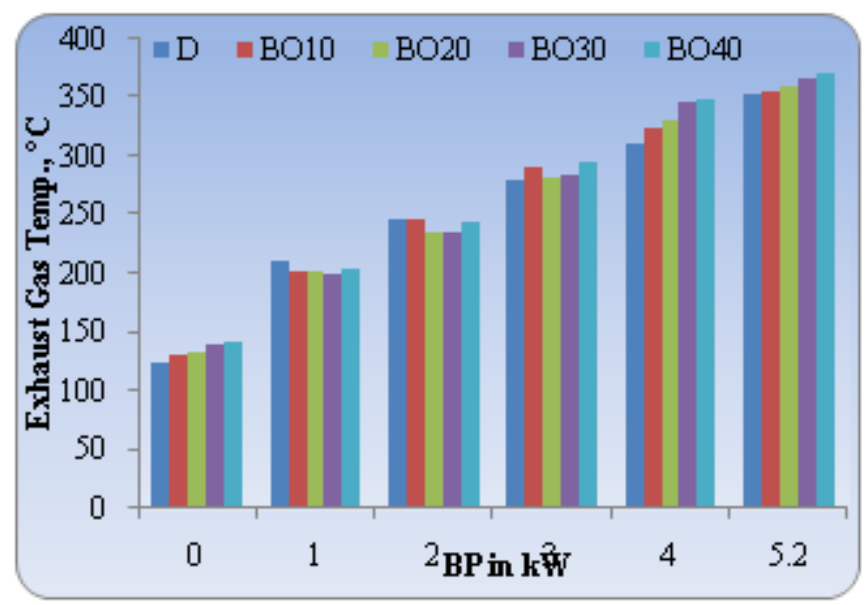

Figure 4: Variation of EGT with brake power

EGT provides qualitative information about the progress of combustion in engine. Figure 4 shows the effect of brake power on exhaust gas temperatures with increase in load. EGT is found to more when compared to diesel and even it was to be found to be increasing with increased emulsions. For diesel, EGT increased from $123.71{ }^{\circ} \mathrm{C}$ at no load to $352.64{ }^{\circ} \mathrm{C}$ at full load. EGT increased from 130.75 to 355.08 ${ }^{0} \mathrm{C}$ for $\mathrm{BO} 10,133.28$ to $360.51{ }^{0} \mathrm{C}$ for $\mathrm{BO} 20,140.14$ to $366.75{ }^{\circ} \mathrm{C}$ for BO30 and 141.14 to $370.1{ }^{\circ} \mathrm{C}$ for B40 with increase in load.

This increase in EGT with load is from the simple fact that more amount of fuel was required in the engine to generate extra power required to take up the additional loading resulting in a delayed combustion or due to increased heat losses at higher emulsions. This increase in the EGT may be due to, presence of oxygen and the high viscosity of the MBO emulsions than diesel. High viscosity fuel is injected up to later part of premixed combustion and there is increased in ignition delay and rapid combustion is formed which lead to high exhaust temperature.

\subsection{Emission Parameters}

\subsubsection{Smoke emissions}

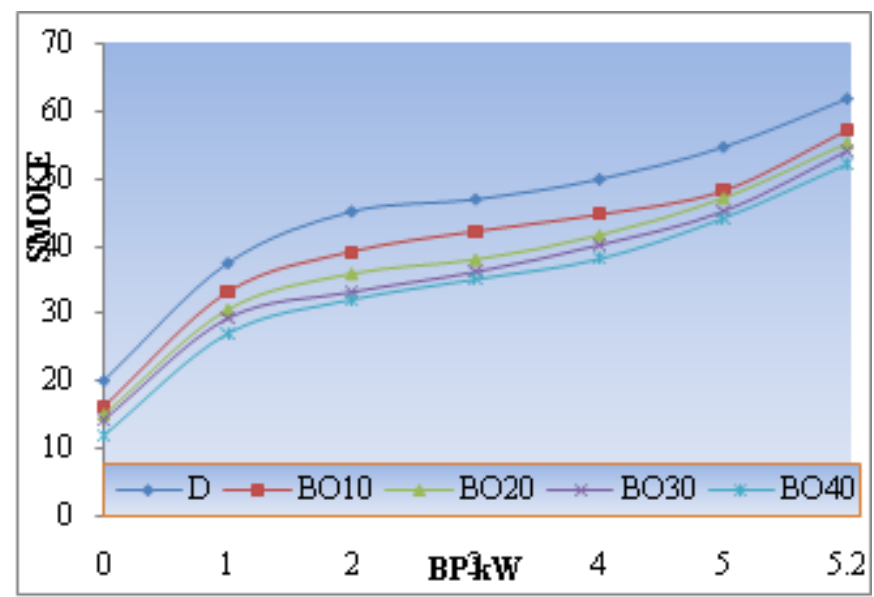

Figure 5: Variation of smoke with brake power

Smoke density is dependent on presence of oxygen in the fuel and the amount of air in the cylinder. It is evident that fuel composition affects the amount of smoke produced by an engine. It is observed from Figure 5 that the smoke emissions for MBO emulsions are lower than that of diesel and smoke value increases with increase in load. The higher oxygen content of bio-oil fuel provided more oxygen for combustion. Thus, the oxygen content present in bio-oil is more effective in reducing smoke emissions.

\subsubsection{NO emissions}

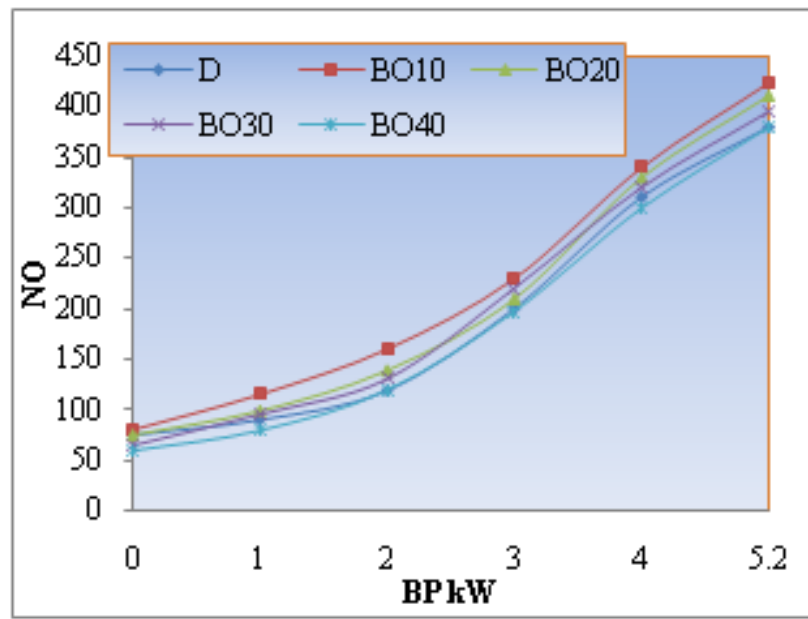

Figure 6: Variation of nitrogen oxide with brake power

NO formation in a compression ignition engine depends on the oxygen availability and combustion temperature. Figure 6 indicates that as the brake power increases the oxides of nitrogen emissions also increases. The NO emissions are found to be higher in the case of emulsions when compared with that of diesel and this may be due to the oxygen content in emulsions. It can be seen that the oxides of nitrogen emissions decreases with blend ratio. The probable reason may be due to heat release caused by the lower heat content of pyrolysis oil by increasing the oil percentage in blending.

\section{Conclusion}

Pyrolysis process is a feasible method for bio-mass conversion into bio-oil. MBO is denser, highly viscous and calorific value is less than the commercial fuels which makes it not suitable to use in diesel engines. Major problem with the bio-oil is its miscibility with diesel fuel, which can be solved by up-gradation of bio-oil by emulsification process. DEE is added $8 \%$ as ignition improver and tween20 is added $2 \%$ as surfactant for stable emulsion of $\mathrm{BO} 10$, $\mathrm{BO} 20, \mathrm{BO} 30$ and $\mathrm{BO} 40$.

The Performance and emissions characteristics of a diesel engine fuelled with diesel and MBO emulsions were experimentally investigated. Brake thermal efficiency of the engine operated with $\mathrm{MBO}$ emulsions was found to be higher than that of diesel. Exhaust gas temperature is found to more when compared to diesel and even it was to be found to be increasing with increased emulsions. This is due to more oxygen availability in the pyrolysis oil and increased combustion duration. The smoke and NO emissions are found to be reduced in the case of emulsions when compared with that of diesel. 


\section{International Journal of Science and Research (IJSR) \\ ISSN (Online): 2319-7064}

Index Copernicus Value (2015): 78.96 | Impact Factor (2015): 6.391

\section{References}

[1] A.V. Bridgwater "Review of fast pyrolysis of biomass and product upgrading" Biomass and Bioenergy $38 \mathrm{pp}$. 68-94, 2012.

[2] Mohammad I. Jahirul 1,2, Mohammad G. Rasul, Ashfaque Ahmed Chowdhury 1 and Nanjappa Ashwath, "Biofuels Production through Biomass Pyrolysis -A Technological Review", Energies, 5, pp. 4952-5001, 2012.

[3] Vikranth Volli, R.K. Singh "Production of bio-oil from de-oiled cakes by thermal pyrolysis" Fuel 96, pp. 579585, 2012.

[4] Dinesh Mohan, Charles U. Pittman, Jr. and Philip H. Steele, "Pyrolysis of Wood/Biomass for Bio-oil: A Critical Review", Energy \& Fuels, 20, pp. 848-889 2012.

[5] S. Muruganan, Sai Gub, "Research and development activities in pyrolysis - Contributions from Indian scientific community - A review", Renewable and Sustainable Energy Reviews 46, pp 282-295, 2015.

[6] Pani Sharanappa, Mallinath. C. Navindagi, A Study Of Fuel Properties Of Ternary Blend Diesel-Mahuva Methyl Ester-Ethanol" special issue IJMPE pp. 1-5 sept. 2016

[7] Niraj Kumar Nayan, Sachin Kumar, R.K. Singh "Characterization of the liquid product obtained by pyrolysis of karanja seed", Bioresource Technology 124, pp 186-189, 2012.

[8] Ozlem Onay, O. Mete Kockar, "Slow, fast and flash pyrolysis of rapeseed", Renewable Energy 28, pp. 2417-2433, 2003.

[9] A. Demirbas "Bio-fuels from Agricutural Residues" Energy Sources, Part A: Recovery, Utilization, and Environmental Effects, 30:2, pp. 101-109, 2007.

[10]S. Czernik and A. V. Bridgwater "Overview of Applications of Biomass Fast Pyrolysis Oil", Energy \& Fuels, 18, pp. 590-598, 2004

[11]A. Oasmaa, "Norms and Standards for Pyrolysis Liquids. End-User Requirements and Specifications",2005

[12]Chiaramonti D, Riccio G, "Sprays of biomass pyrolysis oil emulsions: modelling and experimental investigation. Preliminary results on modelling"

[13]Vikranth Volli, R. K. Singh, S. Murugan, "The Use of Mustard Cake Pyrolytic Oil Blends as Fuel in a Diesel Engine, Waste Biomass", Springer 2012

[14]Babita Singh, Dulari Hansdah, S.Murugan, "Performance and Exhaust Emissions of a Diesel Engine Using Pyrolysis Oil from Waste Frying Oil and Castor Oil Mixture", International Conference On Sustainable Mobility, 2010.

[15]R.Prakash, R.K.Singh, S.Murugan "Utilization of Biomass Based Fuel in a Naturally Aspirated Diesel Engine", Mechanical Engineering Tracks of 3rd Nirma University International Conference (NUICONE 2012)

[16]P. Weerachanchai, C. Tangsathitkulchai, and $\mathrm{M}$. Tangsathitkulchai "Phase behaviors and fuel properties of bio-oil-diesel-alcohol blends", World Academy of Science, Engineering and Technology 322009.

\section{Author Profile}

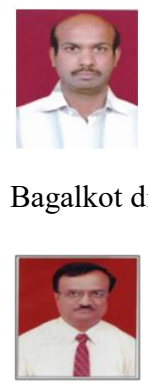

H V Mulimani: Research scholar, pursuing $\mathrm{PhD}$ in Visweshvarayya Technological University, Karnataka, India. Presently working as HOD in Dept. of Mechanical Engineering at Biluru Gurubasava Mahaswamiji Institute of Technology Mudhol Coordinator PG (Thermal Power Engineering) in PDA College of Engineering, Kalburgi, Karnataka, India. He has published many research papers in national and international journals. 